\title{
RIWAYAT PENGGUNAAN ALAT KONTRASEPSI PADA WANITA MENOPAUSE
}

\author{
Budi Astyandini ${ }^{1}$ Rozikhan ${ }^{2}$ Titi Mursiti ${ }^{3}$ \\ 1,2,3 UPPKampus Kendal,PoltekkesKemenkes Semarang, Indonesia \\ email: budiastyandini \\ ABSTRACT
}

\begin{abstract}
A woman's reproductive cycle begins at menarche and ends with menopause. Various factors affect a person's age at menopause. The purpose of this study was to find out the fun of using contraception and the age of menopause that occurred in PERIP administrators in Kendal district. research methods with observational analytics with a retrospective approach. The population in the study was 60 people in the management of PERIP with a total sample of 40 people selected by random sampling, primary data collection using instruments using a questionnaire filled directly by respondents, research results obtained $55 \%$ of respondents using non hormonal contraceptives especially IUDs and menopause age $70 \%$ occurred after age 55 years. The results of the study concluded that most of the non-hormonal contraception methods of menopause were mostly above 55 years. It is recommended for further research to intervene in early menopausal women and test the relationship between variables.
\end{abstract}

\section{Keyword : menarche, Menopause, IUD, contraception}




\section{PENDAHULUAN}

Program Indonesia sehat merupakan prioritas dalam pembangunan nasional saat ini. dalam program Indonesia sehat yang terdiridari 12 indikator salah satu yang penting adalah tiap keluarga telah mengikuti program keluarga berencana. dengan harapan tercipta keluarga yang sehat dan sejahtera. seluruh elemen masyarakat dan lembaga pemerintahan turut serta mendukung program tersebut dengan menggunakan berbagai media. (Depkes RI, 2018)

Pelayanan kontrasepsi terdapat di semua lini tempat kesehatan mulai dari tingkat paling dasar dari kader dan posyandu ke praktik mandiri bidan Puskesmas dan klinik serta RS baik milik pemerintah atau swasta telah secara bersinergi melakukan pelayanan dan melakukan rujukan kasus sebagai bentuk pengayoman bagi seluruh akseptor KB. tenga sarana dan prasarana telah disediakan oleh pemerintah sejak awal program melalui program safari keluarga berencana, manunggal abri dengan kesehatan serta bekerjasama dengan JKN. (Puspitasari, Puspitawati and Herawati, 2013)

Tiap wanita yang mengikuti program keluarga berencana dapat memilih satu diantara berbagai alat dan metode kontrasepsi yang tersedia. Keberagaman jenis alat dan metode menuntut kesimbangan dalam pengetahuan bagi masyarakat tentang segala kelebihan manfaat dan efek samping dari macam alat kontrasepsi. dengan pemahaman dan sikap yang baik dari masyarakat maka kelesetarian akseptor dapat di capai dan akhirnya kesejahteraan keluarga juga aka tercipta . berbagai factor mempengaruhi wanita dalam memilih suatu alat kontrasepsi.('PENERAPAN ANALISIS REGRESI LOGISTIK PADA PEMAKAIAN ALAT KONTRASEPSI WANITA', 2013)

Penelitian Hidayah tahun 2018 didapatkan pada wanita yang memasuki usia menopause akan mulai mengalami gangguan siklus mestruasi. secara fisologis menopause merupakan puncak dari reproduksi wanita. Waktu saat wanita tidak mengalami menstruasi yang telah dialami sejak usia remaja saat pertamakali mengalami menarche. .Faktor yang mempengaruhi terjadinya menopause juga dipengaruhoi oleh kadar hormone didalam tubuh wanita (Hidayah and Dwi Savitri, 2018)

Dari survey pendahuluan yang dilakukan pada pengurus PERIP Kabupaten Kendal didapatkan dari 10 orang ibu yang sudah mengalami menopause 7 diantaranya pernah menjadi akseptor KB hormonal. berdasarkan latar belakang tersebut peneliti tertarik untuk melakukan penelitian yang bertujuan mengetahui gambaran riwayat penggunaan alat kontrasepsi dengan usia menopause pada pengurus PERIP Kabupaten Kendal.

\section{METODOLOGI PENELITIAN}

Metode penelitian ini adalah analitik observasional dengan menggunakan 
pendekatan retrospektif dengan melihat usia menopause yang dialami ditinjau kebelakang riwayat akat kontrasepsi yang pernah digunakan. Populasi penelitian ini berjumlah 60 orang pengurus PERIP Kabupaten Kendal. pengambilan sampel dalam penelitian ini dilakukan secara random dan jumlah sampel yang di gunakan adalah 40 orang dengan criteria inklusi hadir dalam pertemuan rutin pada bulan Juli dan Agustus 2019 dan telah mengalami menopause. Instrument pengumpualan data menggunakan data primer dengan pengisian kuesioner yang langsung dibagikan peneliti saat kegiatan pertemuan PERIP di Kabupaten Kendal. responden telah mendapatkan penjelasan dan mengisi pernyataan informed consent. selanjutnya data akan di oleh untuk mengetahui distribusi frekuensi untuk melihat gambaran masing - masing variable penelitian.

\section{HASIL PENELITIAN DAN BAHASAN}

hasil penelitian tentang metode kontrasepsi yang digunakan responden. sebagai berikut :

Tabel 1. Distribusi frekuensi responden berdasarkan metode kontrasepsi

\begin{tabular}{lcc}
\hline Metode & $F$ & $\%$ \\
\hline Hormonal & 18 & 45 \\
Non Hormonal & 22 & 55 \\
& & \\
\hline Total & 40 & 100 \\
\hline
\end{tabular}

Hasil penelitian dalam Tabel 1 sebagian besar menjadi akseptor $\mathrm{Kb}$ non hormonal 22 orang ( $55 \%$ ) dan sebagian kecil menggunakan hormonal 18 orang ( $45 \%$ )

Responden sebagian besar menggunakan alat kontrasepsi nn hormonal yaitu menggunakan spiral atau IUD dan kondom. berdasarkan data dari wawancara mendalam didapatkan alasan sebagaian besar menggunakan iud karena pada saat responden berusia subur sedang digalakan kegiatan safari KB dan kegiatan TNI manunggal KB Kes, sebagai Istri Perwira maupun ABRI semangat untuk menjadi pelopor dan panutan bagi anggota dan masyarakat mendorong untuk menjadi akseptor $\mathrm{Kb}$. Istri TNi ingin membuktikan semangat bersatu mendukung program pemerintah untuk ambil bagian menguatkan bangsa dengan melibatkan seluruh masyarakat. Tantangan yang dihadapai bangsa Indonesia adalah budaya banyak anak banyak rejeki. dalam berbagai jenis permainan dan pekerjaan saat itu membutuhkan banyak anak. sehingga jiwa patriotism juga muncul dari para anggota perib yang saat itu masih mendampingi suami dalam berkarya. program KB yang sering di lakukan adalah pemasangan IUD. sehingga jumlah akseptor IUD sangat banyak.(Kemenkes RI, 2018)

Sesuai dengan penelitian Nomleni tahun 2014 dalam meilih kontrasepsi IUD factor terpenting adalah pengetahuan ibu tentang IUD dan dukungan dari suami. 
agar setelah pemasanagan kontrasepsi tersebut pemenuhan kebutuhan seksual tidak terganggu. serta keunggulan dan jangka waktu yang panjang memberikan keleluasaan seorang ibu dalam mengatur pengeluaran rumah tangga selain utnuk kontrasepsi.(Nomleni, Ernawati and Mato, 2014)

Penelitian ini sedikit berbeda dengan penelitian hasil penelitian Mariati 2018 yang menyebutkan bahwa hanya $21 \%$ suami yang mendukung istri menggunakan alat kontrasepsi IUD. dengan berbagai alasan dan latar belakang suami tidak mendukung terutama jika pengetahuan tentang iud kurang serta mitos tentang kelemahan IUD yang akan dapat menganggu hubungan seks serat menimbulkan gangguan pada janin atau factor lain dapat memicu sikap suami yang tidak mendukung (Mariati, 2018)

dengan pemberian subsidi dan bantuan dana sehingga pelayanan IUD dapat dilakukan secara gratis dapat menjadi alternative sebagai bahan pertimbnagan bagi suami dalam mendukung istri memilih menjadi akseptor Kb IUD (kurniati, 2012)

Table 2. Distribusi frekuensi responden berdasarkan Usia menopause

\begin{tabular}{lll}
\hline Lama & $\mathrm{F}$ & $\%$ \\
\hline$<55$ tahun & 12 & 30 \\
$>55$ tahun & 28 & 70 \\
\hline
\end{tabular}

$\begin{array}{lll}\text { Total } & 40 & 100\end{array}$

Dari hasil penelitian sebagian besar responden mengalami menopause pada usia diatas 55 tahun sebanyak 28 orang ( $70 \%$ ) sedangkan responden yang mengalami menopause sebelum usia 55 tahun hanya 12 orang ( $30 \%$ )

Factor penyebab menopause pada wanita dipengaruhi oleh berbagai factor baik dari dalam fisik, psikologis maupun social. Pada responden yang mengalami menopause setelah usia 55 tahun didapatkan data pendukung karena usai menarche atau menstruasi mereka umumnya terjadi setelah usia 12 tahun serta besarnya tanggung jawab yang harus dikerjakan pada saat suami bertugas jauh dari rumah, seorang wanita akan melaksanakan beban ganda ketidak seimbangan gender yang terjadi adalah doble garda. wanita selain sebagai ibu juga berfungsi sebagai wakil kepala keluarga yang harus menyelesaikan permasalahan dan mengambil keputusan tegas bagi pemenuhan kebutuhan keluarga. kondisi psikologis dapat menyebabkan menopause menjadi sedikit terhambat.

Hasil penelitian Dewi 2018 seoarang wanita mengalami menopause dapat dipengaruhi oleh factor dari dalam dirinya atau endogen maupun factor dari luar dirinya atau eksogen. kedua factor tersebut akan mempengaruhi situasi psikologis wanita. factor dari dalam dirinya .persepsi penerimaan dan kematangan sesorang akan membantu dalam 
beradaptasi terhadap tekanan yang dialami sedangkan dukungan dari suami kepercayaaan dari pasangan hidup merupakan motivasi yang dapat meningkatkan keseimbangan emosional sesoarang terutama wanita seputar menopause (Dewi, 2018)

Usia menophause dapat dipengaruhi oleh usia menarche seseorang. berdasarkan penelitian Ratna tahun2014 didapatkan bahwa pada wanita yang mengalami menarche usia 19 tahun akan mengalami menopause pada usia sekitar 45 tahun, atau semakin muda seorang wanita mengalami menarche maka semakin tua usia menopausenya. fisologi ini berhubungan dengan otak terutama di hypothalamus dan hypofise serta uterus dan ndung telur yang akan selalu berproses sesuai dengan produksi hormone yang dihasilkan serta kelancaran jalur sirkulasi diantara sel target masing msing hormone reproduksi wanita.(Ratna, 2014)

\section{KESIMPULAN}

Usia menopause pada wanita sangat bervariasi sebagain besar mengalami menopause setelah usia 55 tahun dan sebagian besar pernah menjadi akseptor KB non hormonal. menopause disebabkan oleh factor dari dalam dan luar wanita.peelitian selanjutnya diharapkan dapat meneliti factor yang berhubungan dengan menopause sertaintervensi pada wanita yang mengalami menopause dini.

\section{DAFTAR PUSTAKA}

Depkes RI (2018) Kementerian Kesehatan Republik Indonesia, Kementerian

Kesehatan RI.

Dewi, M. K. (2018) 'Pengukuran Empat

Faktor yang Mempengaruhi Tingkat Stress pada Wanita Menopause', Jurnal Ilmiah

Kebidanan Indonesia. doi:

10.33221/jiki.v8i03.160.

Hidayah, N. and Dwi Savitri, U. (2018)

'RIWAYAT PENGGUNAAN ALAT

KONTRASEPSI (KB) DENGAN

PERUBAHAN FISIK PADA

MENOPAUSE', Jurnal IImu Keperawatan

dan Kebidanan. doi:

10.26751/jikk.v9i1.407.

Kemenkes RI (2018) ‘Hasil Utama Riset

Kesehatan Dasar Tahun 2018',

Kementrian Kesehatan Republik

Indonesia. doi: 1 Desember 2013.

kurniati (2012) kajian SDM kesehatan di indonesia, salemba medika. doi:

10.35329/jkesmas.v5i1.308.

Mariati, T. (2018) 'Dukungan Suami

Dengan Pemilihan Pengunaan

Kontrasepsi Intra Uterine Device (IUD)', Jurnal Manajemen Kesehatan Yayasan RS.Dr. Soetomo. doi:

10.29241/jmk.v4i2.112.

Nomleni, M., Ernawati, E. and Mato, R. (2014) 'FAKTOR-FAKTOR YANG BERHUBUNGAN DENGAN PEMILIHAN ALAT KONTRASEPSI INTRA UTERINE DEVICE (IUD) PADA IBU POST PARTUM NORMAL DI RSKD IBU DAN ANAK SITI FATIMAH MAKASSAR', Jurnal IImiah Kesehatan Diagnosis. 


\section{'PENERAPAN ANALISIS REGRESI}

\section{LOGISTIK PADA PEMAKAIAN ALAT}

KONTRASEPSI WANITA' (2013) Saintia

Matematika.

Puspitasari, N., Puspitawati, H. and

Herawati, T. (2013) 'Peran Gender,

Kontribusi Ekonomi Perempuan, dan

Kesejahteraan Keluarga Petani

Holtikultura', Jurnal Ilmu Keluarga dan

Konsumen. doi:

10.24156/jikk.2013.6.1.10.

Ratna, A. (2014) 'HUBUNGAN

MENARCHE TERHADAP MENOPAUSE

DI KECAMATAN LALABATA KAB.

SOPPENG SULAWESI SELATAN', e-

CliniC. doi: 10.35790/ecl.2.1.2014.3670.

WHO, 2014 (2014) 'Angka kematian ibu',

Jurnal IImiah Kebidanan Indonesia. doi:

10.33221/jiki.v10i01.423. 